\title{
Pragmatic Inferences in High-Functioning Adults with Autism and Asperger Syndrome
}

\author{
Judith Pijnacker $\cdot$ Peter Hagoort · Jan Buitelaar • \\ Jan-Pieter Teunisse $\cdot$ Bart Geurts
}

Published online: 4 December 2008

(C) The Author(s) 2008. This article is published with open access at Springerlink.com

\begin{abstract}
Although people with autism spectrum disorders (ASD) often have severe problems with pragmatic aspects of language, little is known about their pragmatic reasoning. We carried out a behavioral study on highfunctioning adults with autistic disorder $(n=11)$ and Asperger syndrome $(n=17)$ and matched controls $(n=28)$ to investigate whether they are capable of deriving scalar implicatures, which are generally considered to be pragmatic inferences. Participants were presented with underinformative sentences like "Some sparrows are
\end{abstract}

J. Pijnacker $(\varangle) \cdot$ P. Hagoort

Donders Institute for Brain, Cognition and Behaviour,

Radboud University Nijmegen, P. O. Box 9101,

6500 HB Nijmegen, The Netherlands

e-mail: j.pijnacker@fcdonders.ru.nl

\section{P. Hagoort}

Max Planck Institute for Psycholinguistics, Nijmegen,

The Netherlands

J. Buitelaar

Department of Psychiatry, Radboud University Nijmegen

Medical Centre, Nijmegen, The Netherlands

J. Buitelaar

Karakter Child and Adolescent Psychiatry University Centre,

Nijmegen, The Netherlands

J.-P. Teunisse

Dr. Leo Kannerhuis-Centre for Autism, Doorwerth,

The Netherlands

J.-P. Teunisse

Department of Medical Psychology, Radboud University

Nijmegen Medical Centre, Nijmegen, The Netherlands

B. Geurts

Department of Philosophy, Radboud University Nijmegen,

Nijmegen, The Netherlands birds". This sentence is logically true, but pragmatically inappropriate if the scalar implicature "Not all sparrows are birds" is derived. The present findings indicate that the combined ASD group was just as likely as controls to derive scalar implicatures, yet there was a difference between participants with autistic disorder and Asperger syndrome, suggesting a potential differentiation between these disorders in pragmatic reasoning. Moreover, our results suggest that verbal intelligence is a constraint for task performance in autistic disorder but not in Asperger syndrome.

Keywords Autistic disorder - Asperger syndrome . Pragmatics - Inferences - Scalar implicatures .

Language understanding

\section{Introduction}

In everyday discourse, the meaning of an utterance usually goes beyond its explicit linguistic meaning. For example, consider the following dialogue:

(a) A: Would you like some chicken soup?

(b) B: I am a vegetarian.

B's answer seems irrelevant, unless a pragmatic inference is made. In order to understand her reply, one must infer that vegetarians do not eat chicken, and therefore she does not want to have chicken soup. This inference is a pragmatic one, because it is not entailed by the literal content of B's utterance.

Over the past decades, research on autism spectrum disorders (ASD) has shown that pragmatic impairments are widespread in ASD. Pragmatic impairments are found in both children and adults with autistic disorder and Asperger syndrome, whereas formal language deficits (i.e. deficits in 
syntax, semantics, phonology) are not defining features of ASD (DSM-IV 1994) and show a wide variability among persons with ASD (Kjelgaard and Tager-Flusberg 2001; Tager-Flusberg 2006). In this paper, we focus on highfunctioning ASD, that is, ASD without intellectual disability, usually defined as having an intelligence of 85 or above. Research indicates that high-functioning people with ASD usually have relatively intact core language features (Minshew et al. 1995), although others suggest mild to moderate impairments (see also overviews by Boucher 2003; Walenski et al. 2006). What is universal in ASD are severe problems with pragmatic aspects of language (Baron-Cohen 1988; Boucher 2003; Eales 1993; Martin and McDonald 2003; Ozonoff and Miller 1996; Tager-Flusberg 1981, 1996) as is shown, for example, by inappropriate turn-taking in conversations, abnormal prosody, inability to adjust to the communicative setting (e.g., impoliteness, embarrassing questions, pedantic speech), and difficulties in differentiating between old and new information. Furthermore, difficulties in understanding non-literal language have been observed. People with ASD tend to interpret irony and metaphors literally and have difficulty understanding humor (Dennis et al. 2001; Emerich et al. 2003; Happé 1993, 1995; Martin and McDonald 2004).

Despite the considerable amount of literature on pragmatics in ASD, there is a paucity of research on pragmatic reasoning, that is, the ability to make inferences that go beyond the linguistic meaning of utterances. Studies that have examined pragmatic inferences in ASD have focused on bridging inferences and global inferences required for text interpretation (Dennis et al. 2001; Jolliffe and BaronCohen 1999, 2000). People with ASD were found to be less able to use contextual information to make a global inference in a sentence arrangement task (Jolliffe and Baron-Cohen 2000), and were less likely to choose a bridging inference to make a scenario coherent if they had to select from a list of alternatives (Jolliffe and BaronCohen 1999). These findings indicate that people with autism have difficulty understanding language in context, and it has been argued that these findings support the weak central coherence account of ASD. The weak central coherence account claims that people with ASD have a processing bias for details at the expense of the global picture (Frith 2003; Happé 1999; Happé and Frith 2006). Evidence for this pattern has been found in various visual tasks (Jolliffe and Baron-Cohen 2001), as well as in linguistic tasks (Happé 1997; Jolliffe and Baron-Cohen 2000). For example, in a homograph task, in which the correct pronunciation of a word was determined by the preceding sentence, participants with ASD failed to use the correct pronunciation and thus presumably did not fully integrate linguistic information in context (Frith and Snowling 1983; Happé 1997). For instance, they failed to use the sentence context when pronouncing tear in a sentence like "In her dress/eye there was a big tear" (correctly pronounced as teər in the first case and as tiər in the second case).

However, pragmatic impairments in ASD are usually explained by an impaired theory of mind (Baron-Cohen 1988; Tager-Flusberg 1999a, b). Theory of mind refers to the ability to attribute mental states like intentions, beliefs, and desires to oneself and other people as a means to predict and understand behavior (Baron-Cohen 1995, 2001). Happé (1993) found that there is a close link between pragmatic skills and theory of mind abilities. She found that performance on theory of mind tasks was a good predictor of understanding of non-literal uses of language like metaphors and irony.

In this paper we report on a behavioral experiment that examined a class of pragmatic inferences in high-functioning adults with autistic disorder (HFA) and Asperger syndrome. The focus of this study was on scalar implicatures, which are generally considered to be pragmatic inferences. Central to scalar implicatures is how people interpret terms such as some and or, which are very common in everyday language. Before we discuss the experiment, we will provide an overview of recent experimental and developmental research on implicatures and some theoretical background.

\section{Scalar Implicatures}

As illustrated above in (a), in everyday conversation, the meaning of an utterance is determined not only by its literal content, but also by pragmatic factors. These pragmatic factors are responsible for certain inferences. One type of inference in which pragmatic factors play a role are scalar inferences. Consider the following dialogs:

(c) A: Did all students pass the exam?

(d) B: Some of them did.

(e) A: Does John own any pets?

(f) B: He owns a cat or a dog.

Although speaker B did not explicitly say so, most people will understand his utterances as:

(g) Some but not all students passed the exam.

(h) John owns a cat or a dog but not both.

(g) and (h) are inferences that are known as scalar implicatures. The added components but not all and but not both are not part of the literal content of (d) and (f), but are inferences that arise from certain conversational principles. Following Grice (1975), conversation is driven by a cooperative principle, stating that speakers expect each other to make a "conversational contribution such as is required, at the stage at which it occurs, by the accepted 
purpose or direction of the talk exchange" (Grice 1975, p. 45). This cooperative principle is further elaborated as a set of maxims. Implicatures like $(\mathrm{g})$ and $(\mathrm{h})$ are usually explained by reference to the maxim of quantity. This maxim enjoins the speaker to make his contribution as informative as is required for the purpose of conversation.

People interpret (d) as (g) and (f) as (h), because linguistic expressions like some and or are ordered in scales of informativeness (Horn 1972). For instance, the expressions some and or are associated with the following scales:

(i) <some, many, all $>$

(j) $<$ or, and $>$

Other scales are for instance <may, should, must>, $<$ sometimes, often, always $>$, and $<$ possibly, necessary $>$. Typically, the elements of the scale are ordered by entailment relations. Elements on the right side of the scale are informationally stronger, and therefore logically entail the weaker ones. Thus the expression some is weaker than all, because all logically entails some but not vice versa. Assuming that the speaker is obeying the maxim of quantity, the use of a weaker term like some implies that the stronger forms of the scale (i.e. many, all) do not apply; otherwise the speaker would have used one of these stronger forms instead. Hence, if the speaker had known that all students passed the exams, he would have said so, assuming that he speaker is well informed and being cooperative. This type of reasoning requires one to reason about other people's beliefs, because the listener has to take into account what the speaker might have said but did not. Thus the computation of scalar implicatures requires some form of 'mindreading', i.e., the attribution of intentions and beliefs to others. It is precisely reasoning about other people's minds that people with ASD often find hard to do because of an impaired theory of mind (BaronCohen 1995, 2001).

Though the prevailing view is that scalar implicatures are pragmatic inferences, in which at least some form of reasoning about other people's minds is involved, there are competing approaches that do not postulate any form of 'mindreading' in the derivation of scalar implicatures. Levinson (2000), for example, advocates a default approach. $\mathrm{He}$ argues that scalar implicatures are default inferences that are prompted automatically by scalar expressions. Only at a later stage, when the context is taken into consideration, are the default inferences possibly canceled. Likewise, Chierchia (2004) proposes that scalar inferences are always triggered unless they are inhibited by certain syntactic constraints. However, there are good reasons for doubting that these views are on the right track (Geurts 2008).

Despite a considerable amount of theoretical literature on scalar implicatures, it is less clear as to how they are processed. In the following discussion, we review some experimental studies on scalar implicatures. Recent experimental work on children's interpretation of scalar expressions has shown that young children are more logical (i.e., non-pragmatic or literal) than adults, which is to say, children derive fewer implicatures than adults do (Noveck 2001). When presented with underinformative sentences like "Some giraffes have long necks", $89 \%$ of the children in Noveck's study answered that this statement is true (logical/literal interpretation), while only $41 \%$ of the adults responded true. Other developmental studies have confirmed the finding that children do not derive scalar implicatures to the same extent as adults do, even when given more explicit instructions, a training session or acting out tasks that do not require real world knowledge and which are easier for children (Guasti et al. 2005; Papafragou and Musolino 2003; Pouscoulous et al. 2007). The finding that children's performance improved when manipulating experimental conditions, suggests that it is not merely pragmatic competence as such that is lacking in children, and that limited cognitive resources may be part of the explanation.

That the computation of implicatures requires effortful processing has been shown by studies using reaction times. Bott and Noveck (2004), for example, found that participants needed significantly more time to give pragmatic responses ('false'), as compared to logical responses ('true'), when presented with underinformative statements like "Some elephants are mammals". In another experiment, they found that the number of logical responses increased when participants had less time to respond. These findings indicate that the computation of implicatures is effortful. Also, Breheny et al. (2006) found in reading time experiments that processing an implicature took more time than processing the logical meaning of a scalar expression. All of these results point to an effortful process to arrive at the pragmatic interpretation of a scalar term and suggest that scalar inferences are not derived by default, as proposed by Levinson (2000) and Chierchia (2004).

The main purpose of this article is to investigate whether high-functioning adults with ASD are capable of deriving scalar implicatures. From the perspective of autism research, implicatures are interesting in more than one way. First, it is well known that people with ASD often have problems with pragmatic aspects of language. Most importantly, pragmatic interpretation involves the attribution of intentions and beliefs to other people. As described above, deriving an implicature presumably requires one to reason about what a speaker knows and what he might have said but did not. In other words, it requires reasoning about other people's beliefs, and it is precisely this 'mindreading' that has been shown to be difficult for people with ASD (Baron-Cohen 1995, 2001). Second, people with ASD tend to interpret non-literal language like metaphors, idioms, 
and irony literally (Dennis et al. 2001; Happé 1993, 1995). For these reasons we expect adults with ASD to interpret underinformative sentences more often logically (i.e., literally) than matched controls. A second aim of this paper is to explore how people with ASD process implicatures by assessing reading times and linguistic abilities. Finally, we will take into account the distinction between Asperger syndrome and high-functioning autism (HFA). Although people with Asperger syndrome and high-functioning autistic disorder are characterized by similar features and both are likely to be of average or above average intelligence, Asperger syndrome is differentiated from autistic disorder by an absence of clinically significant delays in early cognitive functioning and early language development, in particular the production of first words by the age of two and of phrases by the age of three (DSM-IV 1994). It is still an issue of debate whether Asperger syndrome is a variant of high-functioning autism or is a distinct and separate disorder (Frith 2004; Macintosh and Dissanayake 2004). Because Asperger syndrome and autistic disorder differ in language development profile, we will consider these conditions separately. Moreover, this study offers an opportunity to look at these conditions using measures independent of diagnostic criteria.

\section{Methods}

\section{Participants}

Participants in this study included 28 high-functioning adults with ASD (autistic disorder (HFA), $n=11$ and Asperger syndrome, $n=17$ ) and 28 matched controls, aged 18-40 years. Both groups consisted of 20 male and 8 female subjects. The groups were matched for handedness, with 24 right-handed and 4 left-handed participants in each group. Clinical and control group were matched on sex, age, and verbal IQ as closely as possible (Table 1).

There were neither significant differences between the ASD group and control group with respect to age, verbal intelligence, performance intelligence, and full scale intelligence $(p>0.1$ for all variables), nor between the
ASD subgroups and the control group $(p>0.1)$. Within the ASD group, HFA and Asperger syndrome did not differ from each other on these variables either except for verbal intelligence, with HFA participants showing a significantly lower verbal intelligence than those with Asperger syndrome $(p=0.013)$. Still, the verbal intelligence of HFA participants was well above average. IQ was assessed with one of the various Wechsler Intelligence scales (WAIS-R, WAIS-III, WISC-R) in participants with ASD, and with a short form of the WAIS consisting of four subtests (Comprehension, Similarities, Block Design, and Picture Completion) in controls.

The diagnoses of autistic disorder and Asperger syndrome were established through expert clinical evaluation based on the DSM-IV criteria for these disorders (DSM-IV 1994). The clinical diagnosis was confirmed by the autism diagnostic interview-revised (ADI-R), which is a semistructured developmental diagnostic interview with parents or caregivers (Lord et al. 1994) and is based on behavior of the participant at the age of 4-5 years old. Seven included participants did not meet one of the four specified cutoffs of the ADI-R. This was mainly due to the fact that most of our participants received a diagnosis of ASD in adulthood and their parents did not recall the relevant data. In the case of two participants it was not possible to do an ADI-R because their parents had passed away. In all these cases, the clinical diagnosis of ASD was beyond doubt, meaning that they satisfied the full DSM-IV criteria for autistic disorder or Asperger syndrome, established by thorough clinical assessment, and presented with the typical clinical presentation of autistic disorder or Asperger syndrome. People with a PDD-NOS diagnosis were excluded as well as those with severe comorbid axis-I conditions like major depressive disorder, anxiety disorders, or ADHD.

The clinical group was recruited from the referrals to the psychiatric outpatient department of the Radboud University Nijmegen Medical Centre, specialized institutes for diagnosis and treatment of autism spectrum disorders, and via the website of the Dutch Autism Association. Data obtained from the clinical group were compared to a control group of 28 typically developing, healthy people. The control group was screened for any history of psychiatric

Table 1 Description of the matching variables age, verbal intelligence $(V I Q)$, performance intelligence $(P I Q)$ and full scale intelligence $(F I Q)$ for the ASD group and control group, and for the subgroups within ASD (HFA and Asperger syndrome)

\begin{tabular}{|c|c|c|c|c|c|c|c|c|}
\hline & \multicolumn{2}{|c|}{$\operatorname{ASD}(n=28)$} & \multicolumn{2}{|c|}{ Control $(n=28)$} & \multicolumn{2}{|c|}{ Autistic disorder (HFA) $(n=11)$} & \multicolumn{2}{|c|}{ Asperger syndrome $(n=17)$} \\
\hline & Mean (SD) & Range & Mean (SD) & Range & Mean (SD) & Range & Mean (SD) & Range \\
\hline Age & $26.8(5.2)$ & $19-40$ & $26.3(5.2)$ & $19-39$ & $25.6(3.8)$ & $20-32$ & $27.6(5.9)$ & $19-40$ \\
\hline VIQ & $117.5(13.6)$ & $93-144$ & $116.3(12.9)$ & $94-135$ & $109.8(11.3)$ & $93-128$ & $122.4(12.8)$ & $100-144$ \\
\hline PIQ & $115.1(14.5)$ & $84-144$ & $121.4(14.1)$ & $94-144$ & $113.7(15.3)$ & $91-144$ & $116.0(14.4)$ & $84-144$ \\
\hline FIQ & 117.9 & $91-140$ & 120.0 & $96-139$ & 112.5 & $91-134$ & 121.5 & $91-140$ \\
\hline
\end{tabular}


disorders (Mini International Neuropsychiatric Interview plus) (Sheehan et al. 1998) and was assessed particularly on features of autism, ADHD and depression by means of three self-report questionnaires: (i) Autism Quotient (Baron-Cohen et al. 2001), (ii) Inventory of Depressive Symptomatology Self-report (Rush et al. 1996) and (iii) ADHD rating scale (Kooij et al. 2005). To ensure that no controls with autistic traits were included, a cutoff score on the Autism Quotient was set at 26 (which is 1.5 SD above the mean of a non-ASD control group, see Baron-Cohen et al. 2001). The mean score of the control group on the Autism Quotient was 12 ( $\mathrm{SD}=4$, range 3-18), whereas the mean score of the ASD group was 34 ( $\mathrm{SD}=9$, range 19-47). The mean score on the Inventory of Depressive Symptomatology Self-report indicated that the ASD group was somewhat more depressed than the control group, but within the ASD group there were no significant differences. None of the participants with ASD had clinically significant depressive symptoms. The mean scores of the ADHD rating scale indicated no ADHD features in either group. All participants were native speakers of Dutch and had no known history of neurological disorder, head injury or reading problems. All participants had normal or correctedto-normal vision.

All participants gave informed consent to participate in the study and were reimbursed for travel expenses and participation. The study was formally approved by the local medical ethics committee. This experiment was part of a larger study, which also examined conditional reasoning in autism.

\section{Materials}

The Dutch materials for the implicature task comprised two kinds of scalar terms: some ("sommige") and or ("of"). We deliberately chose to include two types of scalar terms, because previous studies suggest that there are differences in number of logical responses obtained, depending on what kind of scalar term is used.

There were four conditions for the scalar term some: true universals, underinformatives, false universals and true existentials (Table 2). Statements were constructed using the following ten categories: animals, flowers, trees, tools, insects, birds, musical instruments, fruits, garments, and vehicles. Each category contained eight exemplars of that category, and hence there were 80 exemplars in total. The choice of exemplars was based on a study by Vonk (1978), who investigated prototypical examples of several categories. The most frequent exemplars were chosen for the current study.

Each condition consisted of 20 statements. The statements were presented in two versions to ensure that no participant saw the same exemplar more than once. Half of the participants saw exemplars $1-40$ with the quantifier some (20 underinformatives, 20 true existentials) and exemplars 41-80 with the quantifier all (20 true universals, 20 false universals). The other half of the participants saw the exemplars in the reverse order, i.e., exemplars 1-40 with the quantifier all and exemplars 41-80 with the quantifier some. The two versions were counterbalanced across groups. Furthermore, 40 false fillers like "Some fishes are buildings" ( 20 fillers with some and 20 with all) were included. Fillers were not included in the data analysis. The exemplars were matched on lemma frequency and word length. There were no significant differences in frequency and word length between the conditions $(F(3$, 76) $<1, p=0.78 ; F(3,76)=1.99, p=0.12)$.

The some/all sentences were interspersed with sentences with the scalar term $o r$. There were three conditions for this scalar expression: underinformatives, true disjunctions, and false disjunctions (Table 3). Each condition consisted of 20 statements. The materials were matched on sentence length and mean word length $(F(2,57)<1, p=0.89 ; F(2,57)<1$, $p=0.75$ ).

In total, each participant saw 180 statements: 80 statements for the some/all task, 60 statements for the disjunction task, and 40 fillers. Within the entire set, statements were varied pseudo-randomly in five different orders, so that the same condition never occurred twice in a row. Finally, the experimental statements were preceded by eight practice statements to familiarize the participants with the experimental setup.

\section{Procedures}

The experiment was run on a laptop using the Presentation software package. Participants were instructed to judge whether the statements were true or false. They were
Table 2 Conditions for the scalar term some

\begin{tabular}{lll}
\hline Condition & Example & Truth condition \\
\hline True universals & All sparrows are birds & TRUE \\
Underinformative some & Some sparrows are birds & TRUE = logical; FALSE = pragmatic \\
False universals & All birds are sparrows & FALSE \\
True existentials & Some birds are sparrows & TRUE \\
\hline
\end{tabular}


Table 3 Conditions for the scalar term or

\begin{tabular}{lll}
\hline Condition & Example & Truth condition \\
\hline Underinformative disjunctions & Zebras have black or white stripes & TRUE = logical; FALSE = pragmatic \\
True disjunctions & T-shirts have short or long sleeves & TRUE \\
False disjunctions & Snakes have paws or wings & FALSE \\
\hline
\end{tabular}

instructed to be accurate, but not to think too long about the correct response. Moreover, they were told that the computer recorded their responses and the time they had taken to respond. Each trial consisted of the presentation of a 1-s fixation cross followed by the presentation of the statement. Sentences were presented in the centre of the screen in a white font against a black background. To give their response participants had to press the left or right shift button, which were marked with overlays. To avoid a reaction time bias due to hand preference, the assignment of the right and left button for 'true' responses was counterbalanced across participants. There was an optional rest break half way through the task.

\section{Measurements}

For each participant, response type and reading times were recorded. Reading times were recorded from the time when the statement appeared until the participant made a response. Furthermore, all participants underwent an assessment of their language abilities (semantics, syntax, and phonology) using the subtest Comprehension of the Aachen Aphasia Test (Graetz et al. 1992), the Offline Observation Instrument for Grammatical Comprehension (M.E.D. Wassenaar, P. Hagoort, unpublished manuscript, 1994) and the Auditory Discrimination Task-subtest C (Crul and Peters 1976).

\section{Data Analyses}

We analyzed both the pattern of responses and reading times. Since each condition consisted of twenty items, percentages of correct responses were calculated per condition for each participant. As the distribution of these percentages of responses strongly deviated from a normal distribution, nonparametric Mann-Whitney tests (exact) were carried out to investigate response patterns. In addition, relevant correlations between response outcomes and linguistic abilities were calculated

For the reading time data, individual cutoff values were calculated for each participant as the mean \pm 2 standard deviations over all items. Any value exceeding the cutoff was removed from the data set as were all error trials. ${ }^{1}$ Over all, $8 \%$ of the data were removed (disjunction task: ASD group $8.5 \%$, control group 7.7\%; some/all task: ASD group $7.4 \%$, control group $8.7 \%$ ). Because the distribution of reading times for the some/all task was skewed to the right in both groups, and thus deviated from a normal distribution, a $\log$ transformation was carried out to reduce the skew.

Based on previous findings that pragmatic responders are slower than logical responders (Bott and Noveck 2004; Noveck and Posada 2003) participants were divided into pragmatic responders and logical responders, depending on their response patterns: participants who gave more than $50 \%$ 'false' responses to the underinformative statements belong to the category of Pragmatic Responders, whereas the others belong to the category of Logical Responders. Responder Type was entered as a between-subject factor.

\section{Results}

\section{Analysis of Response Proportions}

The ASD group and control group showed equal rates of logical interpretations for the underinformative conditions "Some sparrows are birds" and "Zebras have black or white stripes" ( $U=317, p=0.22 ; U=391, p=0.99)$. For the some underinformatives, $24 \%$ of the responses were logical in the ASD group, whereas in the control group $29 \%$ of the responses were logical (Table 4). Thus all participants derived the scalar implicature (i.e., pragmatic interpretation) quite often. Underinformative disjunctions elicited more logical interpretations than some: $47 \%$ of the responses were logical in the ASD group, whereas in the control group $46 \%$ of the responses were (Table 4). The groups did not differ significantly on the percentages of correct and error responses across the control conditions (all $p$ 's $\geq 0.1$ ).

Since Asperger syndrome and HFA differ in language development profile, we performed a separate analysis with percentages of logical responses serving as dependent measure and diagnosis as a grouping variable. This analysis

\footnotetext{
${ }^{1}$ Errors are those responses that deviate from the truth conditions as given in Tables 2 and 3.
} 
Table 4 Proportion of responses (\%) for the scalar terms some and or

\begin{tabular}{|c|c|c|c|c|c|c|}
\hline \multirow[t]{2}{*}{ Task } & \multirow[t]{2}{*}{ Condition } & \multirow[t]{2}{*}{ Examples } & \multicolumn{2}{|l|}{ ASD } & \multicolumn{2}{|c|}{ Controls } \\
\hline & & & True & False & True & False \\
\hline \multirow[t]{4}{*}{ SOME } & True universals & All sparrows are birds & 95 & 5 & 93 & 7 \\
\hline & Underinformatives & Some sparrows are birds & 24 & 76 & 29 & 71 \\
\hline & False universals & All birds are sparrows & 2 & 98 & 3 & 97 \\
\hline & True existentials & Some birds are sparrows & 96 & 4 & 95 & 5 \\
\hline \multirow[t]{3}{*}{ OR } & Underinformatives & Zebras have black or white stripes & 47 & 53 & 46 & 54 \\
\hline & True disjunctions & T-shirts have short or long sleeves & 92 & 8 & 94 & 6 \\
\hline & False disjunctions & Snakes have paws or wings & 2 & 98 & 3 & 97 \\
\hline
\end{tabular}

revealed that participants with HFA gave more logical responses to underinformative some than those with a diagnosis of Asperger syndrome $(U=45.5, p=0.022)$ (Fig. 1).

This pattern was also present in underinformative disjunctions, though only at a marginally significant level ( $U=52.5, p=0.052$ ). However, there were no significant differences between HFA participants and controls on the number of logical interpretations $(p>0.1)$. A direct comparison between Asperger's participants and controls revealed that the Asperger's participants drew significantly more scalar implicatures in the some/all-task than controls ( $U=140, p=0.020)$, but not in the disjunction task $(p>0.1)$.

\section{Linguistic Abilities}

To assess whether verbal intelligence plays a role in deriving implicatures, we employed a Pearson's correlation. We found a significant negative correlation between verbal intelligence and number of logical interpretations in

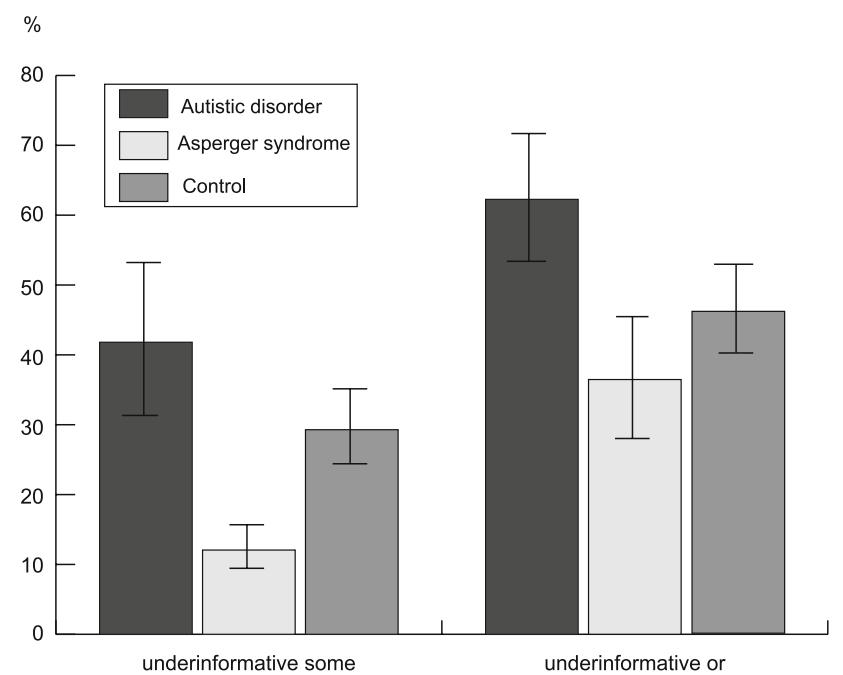

Fig. 1 Mean percentage of logical interpretations for underinformative conditions. Error bars represent $1 \mathrm{SE}$ the HFA group for the some/all task $(r=-0.74$, $p=0.009)$ and a weak trend for the disjunction task ( $r=-0.54, p=0.086)$, indicating that lower verbal IQ scores correlate with a higher number of logical interpretations. In the Asperger group as well as the control group no significant correlations were found between verbal IQ scores and number of logical interpretations (all $p$ 's $>0.1$ ).

To examine language comprehension we used the subtest Comprehension of the Aachen Aphasia Test (Graetz et al. 1992). The maximum score on this subtest is 120 . A score in the range 90-106 indicates mild language comprehension problems. We found that the HFA group scored significantly lower than the Asperger group and control group on this subtest of the Aachen Aphasia Test $(U=35.0, p=0.005 ; U=56.0, p=0.001$, Table 5), however, their mean score was still above the cutoff for mild impairments. The Asperger group and control group did not differ significantly on this subtest $(p>0.5)$.

The Offline Observation Instrument for Grammatical Comprehension was used to assess grammatical skills. The maximum score on this test is 144 . The HFA group scored significantly lower on this test than the Asperger group and the control group $(U=46.5, p=0.022 ; U=70.0$, $p=0.005$, Table 5). It turned out that the HFA group only had difficulties with understanding complex sentences containing a relative clause (e.g., "The woman who pushes

Table 5 Mean, standard deviation and range of scores on the language tests

\begin{tabular}{lllll}
\hline Diagnosis & & AAT $^{\mathrm{a}}$ & Offline gram. $^{\mathrm{b}}$ & ADIT-C $^{\mathrm{c}}$ \\
\hline HFA & Mean (SD) & $108.2(7.1)$ & $139.4(4.1)$ & $46.9(2.8)$ \\
& Range & $95-116$ & $131-143$ & $42-50$ \\
Asperger & Mean (SD) & $114.7(3.6)$ & $141.8(3.1)$ & $45.9(4.2)$ \\
& Range & $107-120$ & $136-144$ & $32-49$ \\
Control & Mean (SD) & $115.0(4.5)$ & $141.8(3.2)$ & $46.7(3.7)$ \\
& Range & $100-120$ & $134-144$ & $30-50$ \\
\hline
\end{tabular}

${ }^{\mathrm{a}}$ Aachen Aphasia Test-subtest Comprehension, ${ }^{\mathrm{b}}$ offline Observation Instrument for Grammatical Comprehension and ${ }^{\mathrm{c}}$ auditory Discrimination Task-subtest C 
the man holds an umbrella"), but not with understanding simple sentences or passives. The groups did not differ significantly on the Auditory Discrimination Task-subtest $\mathrm{C}$, which has a maximum score of 50 .

Although in the HFA group the number of logical responses correlated with verbal intelligence, there were no correlations between number of logical responses and scores on abovementioned language tests $(p$ 's $>0.1)$.

\section{Analysis of Reading Times}

As mentioned before, participants were divided into two groups, depending on their response patterns, because previous findings demonstrated that pragmatic responders are slower than logical responders (Bott and Noveck 2004; Noveck and Posada 2003). In the some/all task, $64 \%$ of the HFA participants, all of the Asperger participants, and $82 \%$ of the control participants were classified as pragmatic responders. In the disjunction task, $27 \%$ of the HFA participants, $76 \%$ of the Asperger participants and $64 \%$ of the control participants were classified as pragmatic responders. Mean reading times for each condition per participant were entered into repeated-measures ANOVAs with Condition as a within-subject factor and Diagnosis and Responder type as between-subject factors.

This analysis showed a main effect of Condition $(F(3,49)=6.64, p=0.001)$ and of Diagnosis $(F(2,51)=$ $4.95, p=0.011$ ) for the some/all task (Fig. 2).

Post hoc tests showed that the HFA group was significantly slower than the Asperger group $(p=0.006)$ and control group $(p=0.010)$. There were no significant

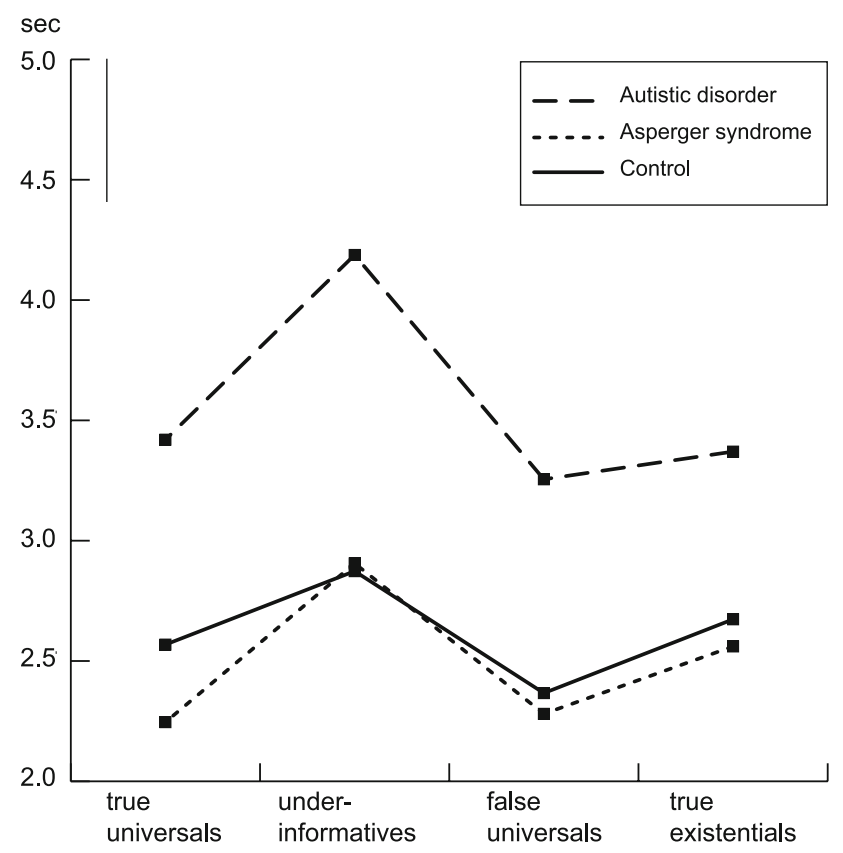

Fig. 2 Mean reading times for the some/all task (in seconds)

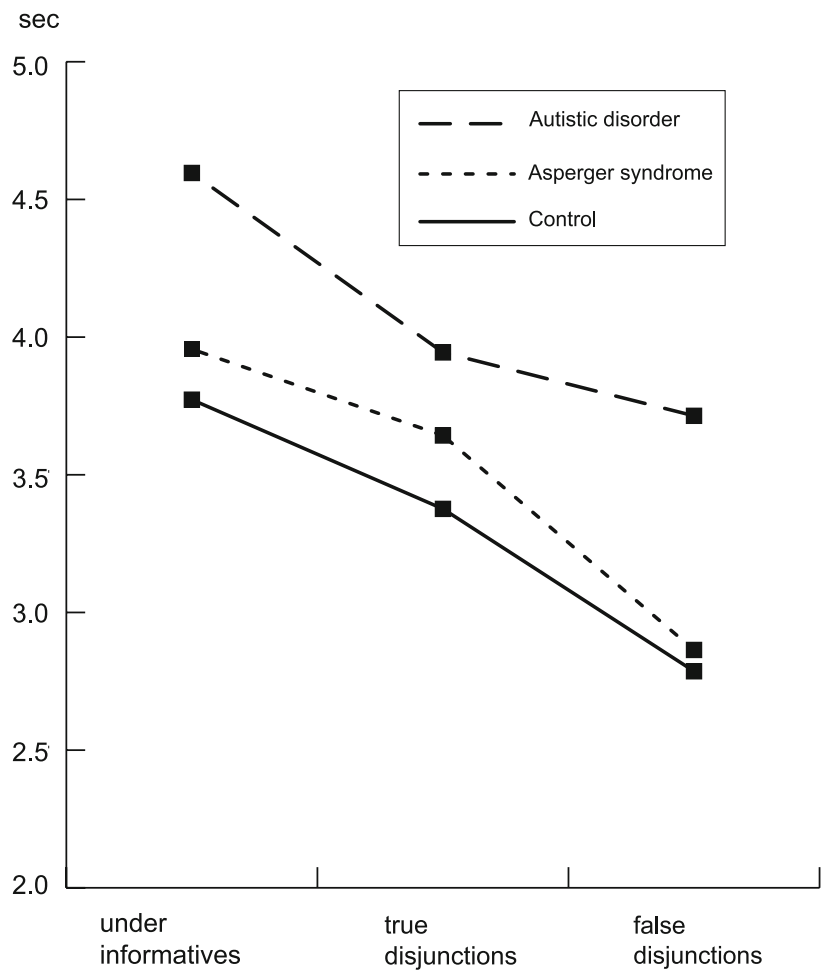

Fig. 3 Mean reading times for the disjunction task (in seconds)

differences in reading times between the Asperger group and controls $(p=0.623)$. The disjunction task also showed a main effect of Condition $(F(2,100)=26.16, p<0.001)$ and of Diagnosis $(F(2,50)=4.01, p=0.024)$ with slower responses for the HFA group than the control group $(p=0.022)$ (Fig. 3).

Moreover, there was an effect of Responder type $(F(1,50)=10.3, p=0.002)$ with slower responses for pragmatic responders than logical responders, and a Condition $\times$ Responder type interaction $(F(2,100)=6.31$, $p=0.003)$ indicating that pragmatic responders needed more time for underinformative disjunctions and true disjunctions but not for false disjunctions, when compared to logical responders (Fig. 4).

Planned paired $t$-tests between underinformative conditions and control conditions revealed that the underinformative conditions took more time to process than control conditions ( $p<0.001$ for all comparisons). However, within the groups, underinformative some and true existentials did not differ significantly in the control group ( $p=0.091)$, and underinformative disjunctions and true disjunctions did not differ in the Asperger group $(p=0.096)$.

\section{Discussion}

Contrary to our expectations, our results demonstrate that on the whole, high-functioning adults with ASD are rather 


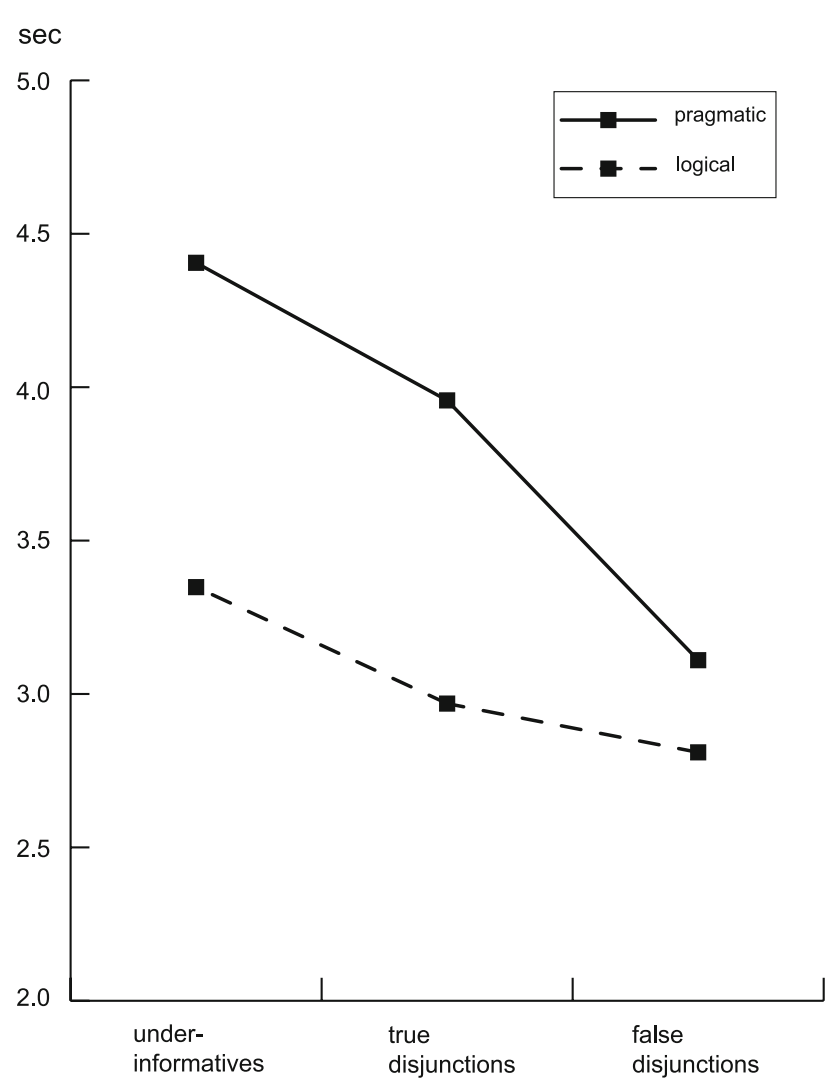

Fig. 4 Mean reading times for logical and pragmatic responders in the disjunction task (in seconds)

good at deriving implicatures. In particular, the performance of the Asperger syndrome group was better than expected: they were as fast as the control group and they were even better at deriving implicatures in the case of the scalar term some. Strikingly, the HFA group derived fewer implicatures than the Asperger group. Participants with HFA more often gave a logical interpretation to underinformative sentences like "Some sparrows are birds" than did participants with Asperger syndrome. Moreover, the HFA participants were slower in responding, which suggests that the task was more difficult for them. Furthermore, in the HFA group the rate of logical interpretations was associated with verbal intelligence: lower verbal intelligence correlated with fewer scalar implicatures. In contrast, we did not find such a correlation either in the control group or in the Asperger group.

A potential but almost inevitable limitation of the present study concerns the significant difference in verbal intelligence between the HFA group and Asperger group. This raises the possibility that the findings are primarily due to a difference in language ability. Indeed, the findings suggest that language ability may be relevant for computing scalar implicatures in HFA. The fact that the rate of scalar implicatures was linked with level of verbal intelligence in the HFA group indicates that verbal intelligence is a constraint on task performance in HFA, and that people with HFA may employ verbal intelligence to compensate for pragmatic deficits. It should be stressed, however, that it is far from clear how exactly verbal intelligence might contribute to the interpretation of scalar expressions. Since verbal intelligence is a general measure with several components (e.g., verbal working memory, concept formation, and factual knowledge), it is hard to tell at this point which of these could be involved in the derivation of implicatures, and what kind of role they might play.

Moreover, it is unclear what role formal language abilities play in deriving implicatures. Assessment of these abilities revealed that the HFA group scored lower on a language comprehension test and a grammaticality test compared to the Asperger group and controls. However, performance of the HFA group on language comprehension was well above the threshold for mild language comprehension problems, and hence the finding that HFA participants derived fewer implicatures cannot be attributed to any particular language comprehension deficiencies. Furthermore, though the HFA group scored lower on the grammaticality test, performance was still close to the maximum level. Errors in grammatical comprehension were restricted to complex sentences containing relative clauses (e.g., "The woman who pushes the man holds an umbrella"), and did not affect simple sentences as used in the current experiment. Finally, the HFA group only showed a correlation between the number of scalar implicatures and level of verbal intelligence, but no such correlations were found for formal language abilities. Perhaps using more sophisticated linguistic measures could reveal what role language abilities play in understanding scalar expressions.

An important issue is how scalar implicatures can be related to two dominant cognitive theories on autism. In the light of the weak central coherence account, it could be argued that a logical interpretation of a scalar expression is due to a processing bias for the local meaning (i.e., the literal or logical meaning) and a disregard of the global meaning (i.e., the pragmatic meaning). However, as mentioned in the introduction, to arrive at the global meaning, some form of theory of mind reasoning is involved. For example, to derive that "Not all students passed their exam" from "Some students passed their exam", the listener must assume that the speaker does not have the belief that all students passed their exam, for otherwise he would have said so. With regard to the dominant cognitive theories on autism, we therefore think that it is more plausible to assume that deriving scalar implicatures is related to the theory of mind account. Moreover, as discussed above, language abilities presumably play a role in scalar implicature, too.

The finding that participants with ASD were as likely as controls to derive scalar implicatures calls for an 
explanation. First, it should be noted that our participants were of average or above average intelligence and it might be that they employed their cognitive capacities for solving the task. Second, and more importantly, we should look at what kind of theory of mind reasoning is involved in scalar implicatures, because the attribution of first-order mental states (e.g., Peter does not know that ...) must be distinguished from the attribution of second-order or higher order mental states (e.g., Peter does not know that John knows that ...). According to Happé (1993), first-order representations involve recognizing a speaker's informative intention, whereas second-order representations involve recognizing communicative intentions. In this perspective, scalar implicatures concern the attribution of first-order mental states, as they involve recognizing the speaker's informative intention. This may explain why participants with ASD did so well on the scalar implicature tasks, since several studies investigating theory of mind task in persons with ASD of average or above average intelligence have shown that a considerable number of such individuals - and those with Asperger syndrome in particular - can pass first-order and even second-order theory of mind tasks (Bauminger and Kasari 1999; Bowler 1992; Buitelaar et al. 1999; Dahlgren and Trillingsgaard 1996; Happé 1994; Ozonoff et al. 1991; Tager-Flusberg and Sullivan 1994). Finally, it is possible that the experimental setting may have facilitated task performance, since communicative demands are reduced in a computerized task (Ozonoff 1995). Future research should focus on the role of theory of mind abilities as well as language abilities in interpreting scalar expressions.

The last point we would like to mention concerns the controversy whether Asperger syndrome is a variant of (high-functioning) autism or a distinct disorder (Frith 2004; Macintosh and Dissanayake 2004). Although a considerable amount of literature has addressed this issue, recent studies are still contradictory. According to Ritvo et al. (2008) Asperger syndrome is a mild form of autism with fewer but similar symptoms. Against this position, Matson and Wilkins (2007) argue that Asperger syndrome can be differentiated from high-functioning autism on a range of symptoms. Although the present findings cannot offer any decisive evidence in favor of one position or the other, they suggest that a differentiation can be made between Asperger syndrome and high-functioning autism in terms of deriving scalar implicatures and of pragmatic reasoning. It appears that the very early distinction between Asperger syndrome and autistic disorder-based on the onset of first words and phrases - continues to exist in adulthood, at least at the level of more subtle and complex linguistic functioning. Therefore, it may be useful for clinical as well as research purposes to distinguish subgroups based on the early language profile within the autism spectrum, and to study the link between these language profiles and pragmatic reasoning over development. We further plan to investigate the neural correlates of pragmatic reasoning in ASD using event-related brain potentials. This would allow us to investigate the processes involved in pragmatic tasks with high temporal resolution.

Acknowledgments We are grateful to the people with ASD and their parents who participated in this research. This project was supported by The Netherlands Organization for Scientific Research under grant NWOCOG/04-19. Finally, we thank Cees Kan, Cathelijne Tesink, Rutger-Jan van der Gaag, Stephan Gemsa and Bram Hochstenbach for their assistance.

Open Access This article is distributed under the terms of the Creative Commons Attribution Noncommercial License which permits any noncommercial use, distribution, and reproduction in any medium, provided the original author(s) and source are credited.

\section{References}

Baron-Cohen, S. (1988). Social and pragmatic deficits in autism: Cognitive or affective? Journal of Autism and Developmental Disorders, 18(3), 379-402. doi:10.1007/BF02212194.

Baron-Cohen, S. (1995). Mindblindness: An essay on autism and the theory of mind. Cambridge: MIT Press.

Baron-Cohen, S. (2001). Theory of mind and autism: A review. Special Issue of the International Review of Mental Retardation, 23, 169-204.

Baron-Cohen, S., Wheelwright, S., Skinner, R., Martin, J., \& Clubley, E. (2001). The autism spectrum quotient (AQ): Evidence from Asperger syndrome/high-functioning autism, males and females, scientists and mathematicians. Journal of Autism and Developmental Disorders, 31, 5-17. doi:10.1023/A:1005653411471.

Bauminger, N., \& Kasari, C. (1999). Brief report: Theory of mind in high-functioning children with autism. Journal of Autism and Developmental Disorders, 29(1), 81-86. doi:10.1023/A:10259 74701090 .

Bott, L., \& Noveck, I. A. (2004). Some utterances are underinformative: The onset and time course of scalar inferences. Journal of Memory and Language, 51(3), 437-457.

Boucher, J. (2003). Language development in autism. International Journal of Pediatric Otorhinolaryngology, 67(suppl 1), 159-163. doi:10.1016/j.ijporl.2003.08.016.

Bowler, D. M. (1992). "Theory of mind" in Asperger's syndrome. Journal of Child Psychology and Psychiatry, and Allied Disciplines, 33(5), 877-893. doi:10.1111/j.1469-7610.1992.tb01962.x.

Breheny, R., Katsos, N., \& Williams, J. (2006). Are generalised scalar implicatures generated by default? An online investigation into the role of context in generating pragmatic inferences. Cognition, 100(3), 434-463.

Buitelaar, J. K., van der Wees, M., Swaab-Barneveld, H., \& van der Gaag, R. J. (1999). Theory of mind and emotion-recognition functioning in autistic spectrum disorders and in psychiatric control and normal children. Development and Psychopathology, 11(1), 39-58. doi:10.1017/S0954579499001947.

Chierchia, G. (2004). Scalar implicatures, polarity phenomenon and the syntax/pragmatics interface. In A. Belleti (Ed.), Structures and beyond (Vol. 3). Oxford: Oxford University Press.

Crul, T. A. M., \& Peters, H. F. M. (1976). Auditieve discriminatietest. Lisse: Swets \& Zeitlinger. 
Dahlgren, S. O., \& Trillingsgaard, A. (1996). Theory of mind in nonretarded children with autism and Asperger's syndrome. A research note. Journal of Child Psychology and Psychiatry, and Allied Disciplines, 37(6), 759-763. doi:10.1111/j.1469-7610. 1996.tb01469.x.

Dennis, M., Lazenby, A. L., \& Lockyer, L. (2001). Inferential language in high-functioning children with autism. Journal of Autism and Developmental Disorders, 31(1), 47-54. doi:10.1023/ A:1005661613288.

DSM-IV. (1994). Diagnostic and statistical manual of mental disorders (4th ed.). Washington DC: American Psychiatric Association.

Eales, M. J. (1993). Pragmatic impairments in adults with childhood diagnoses of autism or developmental receptive language disorder. Journal of Autism and Developmental Disorders, 23(4), 593-617. doi:10.1007/BF01046104.

Emerich, D. M., Creaghead, N. A., Grether, S. M., Murray, D., \& Grasha, C. (2003). The comprehension of humorous materials by adolescents with high-functioning autism and Asperger's syndrome. Journal of Autism and Developmental Disorders, 33(3), 253-257. doi:10.1023/A:1024498232284.

Frith, U. (2003). Autism: Explaining the enigma. Oxford: Blackwell Publishers.

Frith, U. (2004). Emanuel Miller lecture: Confusions and controversies about Asperger syndrome. Journal of Child Psychology and Psychiatry, and Allied Disciplines, 45(4), 672-686. doi:10.1111/ j.1469-7610.2004.00262.x.

Frith, U., \& Snowling, M. (1983). Reading for meaning and reading for sound in autistic and dyslexic children. Journal of Developmental Psychology, 1, 329-342.

Geurts, B. (2008). Scalar implicature and local pragmatics. Mind \& Language, in press.

Graetz, P., De Bleser, R., \& Wilmes, K. (1992). De Akense Afasietest [The Aachen Aphasia Test]. Amsterdam: Swets\&Zweitlinger.

Grice, P. (1975). Logic and conversation. In P. Cole \& J. L. Morgan (Eds.), Studies in syntax. Vol 3: Speech acts (pp. 41-58). New York: Academic Press.

Guasti, M. T., Chierchia, G., Foppolo, F., Gualmini, A., \& Meroni, L. (2005). Why children and adults sometimes (but not always) compute implicatures. Language and Cognitive Processes, 20(5), 667-696. doi:10.1080/01690960444000250.

Happé, F. (1993). Communicative competence and theory of mind in autism: A test of relevance theory. Cognition, 48, 101-119. doi: 10.1016/0010-0277(93)90026-R.

Happé, F. (1994). An advanced test of theory of mind: Understanding of story characters' thoughts and feelings by able autistic, mentally handicapped, and normal children and adults. Journal of Autism and Developmental Disorders, 24(2), 129-154. doi: 10.1007/BF02172093.

Happé, F. (1995). Understanding minds and metaphors: Insights from the study of figurative language in autism. Metaphor and symbol, 275-295(4), 275-295.

Happé, F. (1997). Central coherence and theory of mind: Reading homographs in context. The British Journal of Developmental Psychology, 15, 1-12.

Happé, F. (1999). Autism: Cognitive deficit or cognitive style? Trends in Cognitive Sciences, 3(6), 216-222. doi:10.1016/S1364-6613 (99)01318-2.

Happé, F., \& Frith, U. (2006). The weak coherence account: Detailfocused cognitive style in autism spectrum disorders. Journal of Autism and Developmental Disorders, 36(1), 5-25. doi:10.1007/ s10803-005-0039-0.

Horn, L. R. (1972). On the semantic properties of logical operators in English. University of California: LA.

Jolliffe, T., \& Baron-Cohen, S. (1999). A test of central coherence theory: Linguistic processing in high-functioning adults with autism or Asperger syndrome: Is local coherence impaired? Cognition, 71, 149-185. doi:10.1016/S0010-0277(99)00022-0.

Jolliffe, T., \& Baron-Cohen, S. (2000). Linguistic processing in highfunctioning adults with autism or Asperger's syndrome: Is global coherence impaired? Psychological Medicine, 30, 1169-1187. doi:10.1017/S003329179900241X.

Jolliffe, T., \& Baron-Cohen, S. (2001). A test of central coherence theory: Can adults with high-functioning autism or Asperger syndrome integrate fragments of an object? Cognitive Neuropsychiatry, 6, 193-216. doi:10.1080/13546800042000124.

Kjelgaard, M. M., \& Tager-Flusberg, H. (2001). An investigation of language impairment in autism: Implications for genetic subgroups. Language and Cognitive Processes, 16(2/3), 287-308.

Kooij, J. J. S., Buitelaar, J. K., van den Oord, E. J., Furer, J. W., Rijnders, C. A. T., \& Hodiamont, P. P. G. (2005). Internal and external validity of attention-deficit hyperactivity disorder in a population-based sample of adults. Psychological Medicine: A Journal for Research in Psychiatry and the Allied Sciences, 35, 817-827.

Levinson, S. C. (2000). Presumptive meanings: The theory of generalized conversational implicature. Massachusetts: MIT press.

Lord, C., Rutter, M., \& Le Couteur, A. (1994). Autism diagnostic interview-revised: A revised version of a diagnostic interview for caregivers of individuals with possible pervasive developmental disorders. Journal of Autism and Developmental Disorders, 24(5), 659-685. doi:10.1007/BF02172145.

Macintosh, K. E., \& Dissanayake, C. (2004). Annotation: The similarities and differences between autistic disorder and Asperger's disorder: A review of the empirical evidence. Journal of Child Psychology and Psychiatry, and Allied Disciplines, 45(3), 421-434. doi:10.1111/j.1469-7610.2004.00234.x.

Martin, I., \& McDonald, S. (2003). Weak coherence, no theory of mind, or executive dysfunction? Solving the puzzle of pragmatic language disorders. Brain and Language, 85(3), 451-466. doi: 10.1016/S0093-934X(03)00070-1.

Martin, I., \& McDonald, S. (2004). An exploration of causes of nonliteral language problems in individuals with Asperger syndrome. Journal of Autism and Developmental Disorders, 34(3), 311-328. doi:10.1023/B:JADD.0000029553.52889.15.

Matson, J. L., \& Wilkins, J. (2007). Nosology and the diagnosis of Asperger's syndrome. Research in Autism Spectrum Disorders, 2(2), 288-300.

Minshew, N. J., Goldstein, G., \& Siegel, D. (1995). Speech and language in high-functioning autistic individuals. Neuropsychology, 9(2), 255-261. doi:10.1037/0894-4105.9.2.255.

Noveck, I. A. (2001). When children are more logical than adults: Experimental investigations of scalar implicature. Cognition, 78, 165-188. doi:10.1016/S0010-0277(00)00114-1.

Noveck, I. A., \& Posada, A. (2003). Characterizing the time course of an implicature: An evoked potentials study. Brain and Language, 85, 203-210. doi:10.1016/S0093-934X(03)00053-1.

Ozonoff, S. (1995). Reliability and validity of the wisconsin card sorting test in studies of autism. Neuropsychology, 9(4), 492500. doi:10.1037/0894-4105.9.4.491.

Ozonoff, S., \& Miller, J. N. (1996). An exploration of righthemisphere contributions to the pragmatic impairments of autism. Brain and Language, 52(3), 411-434. doi:10.1006/brln. 1996.0022.

Ozonoff, S., Rogers, S. J., \& Pennington, B. F. (1991). Asperger's syndrome: Evidence of an empirical distinction from highfunctioning autism. Journal of Child Psychology and Psychiatry, and Allied Disciplines, 32(7), 1107-1122. doi:10.1111/j.14697610.1991.tb00352.x.

Papafragou, A., \& Musolino, J. (2003). Scalar implicatures: Experiments at the semantics-pragmatics interface. Cognition, 86, 253-282. doi:10.1016/S0010-0277(02)00179-8. 
Pouscoulous, N., Noveck, I. A., Politzer, G., \& Bastide, A. (2007). A developmental investigation of processing costs in implicature production. Language Acquisition: A Journal of Developmental Linguistics, 14(4), 347-375. doi:10.1080/10489220701600457.

Ritvo, R. A., Ritvo, E. R., Guthrie, D., \& Ritvo, M. J. (2008). Clinical evidence that Asperger's disorder is a mild form of autism. Comprehensive Psychiatry, 49(1), 1-5.

Rush, A. J., Gullion, C. M., Basco, M. R., Jarrett, R. B., \& Trivedi, M. H. (1996). The inventory of depressive symptomatology (IDS): Psychometric properties. Psychological Medicine, 26(3), 477-486.

Sheehan, D. V., Lecrubier, Y., Sheehan, K. H., Amorim, P., Janavs, J., Weiller, E., et al. (1998). The mini-international neuropsychiatric interview (M.I.N.I.): The development and validation of a structured diagnostic psychiatric interview for DSM-IV and ICD-10. The Journal of Clinical Psychiatry, 59(suppl 20), 22-33.

Tager-Flusberg, H. (1981). On the nature of linguistic functioning in early infantile autism. Journal of Autism and Developmental Disorders, 11(1), 45-56. doi:10.1007/BF01531340.

Tager-Flusberg, H. (1996). Brief report: Current theory and research on language and communication in autism. Journal of Autism and Developmental Disorders, 26(2), 169-171. doi:10.1007/ BF02172006.
Tager-Flusberg, H. (1999a). Language and understanding minds: Connections in autism. In S. Baron-Cohen, H. Tager-Flusberg \& D. J. Cohen (Eds.), Understanding other minds: Perspectives from autism and developmental cognitive neuroscience (2nd ed.). Oxford: Oxford University Press.

Tager-Flusberg, H. (1999b). A psychological approach to understanding the social and language impairments in autism. International Review of Psychiatry (Abingdon, England), 11(4), 325-334. doi:10.1080/09540269974203.

Tager-Flusberg, H. (2006). Defining language phenotypes in autism. Clinical Neuroscience Research, 6(3-4), 219-224. doi:10.1016/ j.cnr.2006.06.007.

Tager-Flusberg, H., \& Sullivan, K. (1994). A second look at secondorder belief attribution in autism. Journal of Autism and Developmental Disorders, 24(5), 577-586. doi:10.1007/BF02172139.

Vonk, W. (1978). Categorienormen voor woorden in 34 categorieën. Heymans bulletins, $n r$. HB-78-373.

Walenski, M., Tager-Flusberg, H., \& Ullman, M. T. (2006). Language in autism. In S. O. Moldin \& J. L. R. Rubenstein (Eds.), Understanding autism: From basic neuroscience to treatment (pp. 175-203). Boca Raton: CRC Press Inc. 